\title{
STUDI EVALUASI METODE PENGUKURAN STABILITAS \\ CANDI BOROBUDUR DAN BUKIT
}

Oleh

Joni Setyawan, S.T.

\author{
Balai Konservasi Peninggalan Borobudur
}

\begin{abstract}
ABSTRAK
Candi Borobudur sebagai sebuah peninggalan bersejarah bagi bangsa Indonesia sudah ditetapkan sebagai warisan budaya dunia. Penjagaan dan pelestarian candi Borobudur dari unsur manusia maupun alam perlu dilakukan secara intensif dan periodik. Salah satu bentuk antisipasi pencegahan kerusakan yang terjadi adalah dengan melakukan pemantauan stabilitas struktur candi Borobudur terhadap kemungkinan terjadinya deformasi. Dalam hal ini Balai Konservasi Peninggalan Borobudur telah melakukan pemantauan stabilitas candi Borobudur melalui pengukuran yang secara periodik dan berkelanjutan setiap tahun sejak 1983 sampai dengan sekarang. Permasalahannya adalah pengukuran yang selama ini dilakukan belum memperoleh ketelitian yang diharapkan, sehingga perlu dilakukan evaluasi terhadap peralatan maupun metode pengukuran yang sudah digunakan.
\end{abstract}

Studi dilakukan pada data hasil pengukuran jarak, sudut, dan beda tinggi pada jaring kontrol deformasi poligon III yang berada di halaman atas candi Borobudur. Pengukuran jarak dilakukan dengan alat EDM TS Leica TCR $805 \mathrm{U}$, pengukuran sudut dilakukan dengan alat Theodolit Wild T2 dan TS Leica TCR 805 U, pengukuran sipat datar dilakukan dengan alat Topcon AT G2 dan Leica Sprinter 200M. Untuk menghitung koordinat titik poligon III menggunakan metode Bowditch dan hitung perataan kuadrat terkecil metode parameter. Uji kualitas data dilakukan dengan uji statistik berupa uji global.

Hasil analisa ketelitian alat menunjukkan bahwa Theodolit Wild T2 mempunyai tingkat ketelitian yang lebih tinggi dari TS Leica TCR 805 U, dan Topcon AT G2 dengan rambu ukur invar mempunyai tingkat ketelitian yang lebih tinggi dari Leica Sprinter 200M dengan rambu ukur barcode. Hasil analisa ketelitian metode hitung perataan menunjukkan bahwa dari metode Bowditch hanya dapat diperoleh ketelitian linier dan koreksi perataan hanya memperhitungkan jarak sisi poligon, sedangkan dari hitung perataan kuadrat terkecil metode parameter dapat diperoleh ketelitian dari tiap koordinat titik poligon III dan koreksi perataan juga memperhitungkan bobot yang dapat berupa ketelitian alat maupun ketelitian pengukuran, sehingga koordinat yang diperoleh dari hitung perataan metode parameter lebih tepat dan lebih teliti dari hitung perataan metode Bowditch. Hasil uji global data pengamatan yang digunakan tidak mengandung kesalahan tak acak.

\section{Pendahuluan}

\section{A. Latar Belakang}

Pemantauan stabilitas bangunan di Indonesia masih sangat terbatas pada obyek-obyek yang berkaitan dengan keselamatan manusia seperti dam/bendungan, pertambangan, dan gunung berapi. Pemantauan stabilitas bangunan dapat memperbaiki asumsi desain serta model perhitungan terhadap kondisi yang sebenarnya, yang memberikan penilaian menyeluruh dari bangunan tersebut dibandingkan dengan perilaku yang diperkirakan, dapat untuk merumuskan tindakan pengamanan terhadap penyimpangan yang didapat, bahkan lebih luas lagi dapat meningkatkan ilmu pengetahuan tentang perilaku bangunan dalam mencari kedudukan barunya yang seimbang. Semua ini akan sangat bermanfaat bagi desain di masa mendatang.

Candi Borobudur sebagai sebuah bangunan peninggalan bersejarah bagi bangsa Indonesia telah diakui sebagai salah satu warisan kebudayaan dunia (World Cultural Heritage). Dilihat dari sejarahnya candi Borobudur telah mengalami dua kali pemugaran. Pemugaran yang pertama dilakukan oleh Van Erp pada tahun 1907 - 1911, sedangkan pemugaran yang kedua dilakukan oleh Prof. Dr. R. Soekmono pada tahun 1975 -1983 bekerjasama dengan UNESCO.

Sejak tahun 1983 dengan selesainya pemugaran candi Borobudur, dilakukan pengamatan stabilitas baik pada struktur candi maupun pada bukit pendukungnya. Hal ini sesuai dengan rekomendasi dari hasil pertemuan para ahli dari beberapa negara yang terlibat pada pemugaran candi Borobudur. Pengamatan bagian atas (upper structure) untuk mengetahui adanya kemungkinan perubahan kedudukan candi baik penurunan, kemiringan maupun pergerakan ke arah horisontal.

Berdasarkan rekomendasi UNESCO Expert Meeting, maka team monitoring pemugaran candi Borobudur, dalam hal ini Balai Konservasi Peninggalan Borobudur (BKPB) melakukan pemantauan stabilitas 
candi Borobudur melalui pengukuran yang secara kontinyu setiap tahun sejak 1983 sampai dengan sekarang. Pengukuran tersebut menggunakan metode poligon untuk jaring kontrol horisontal dan metode sipat datar untuk jaring kontrol vertikal. Kemudian dari kedua metode pengukuran tersebut diperoleh informasi geometrik berupa posisi titik-titik jaring kontrol deformasi dalam koordinat XYZ (3 dimensi) sehingga dapat dievaluasi perubahan yang terjadi baik secara horisontal (XY) maupun vertikal (Z).

Dari beberapa studi yang telah dilakukan diketahui bahwa setelah pemugaran yang kedua, candi Borobudur merupakan sebuah bangunan yang relatif stabil. Sehingga untuk mempelajari atau mengetahui pergeseran yang hanya terjadi pada fraksi milimeter diperlukan peralatan dan metode pengukuran yang akan menghasilkan ketelitian yang tinggi dimana ketelitian pengukuran yang diperoleh lebih kecil daripada pergeseran yang terjadi. Permasalahannya adalah pengukuran yang selama ini dilakukan belum memperoleh ketelitian yang diharapkan, sehingga perlu dilakukan evaluasi terhadap peralatan maupun metode pengukuran yang sudah digunakan.

\section{B. Rumusan Masalah}

Studi ini berusaha untuk mengkaji peralatan pengukuran yang tersedia di Balai Konservasi Borobudur, manakah yang memberikan hasil ketelitian yang lebih tinggi untuk pengukuran serta metode penghitungan/perataan apa yang lebih tepat untuk memproses data hasil pengukuran dalam rangka untuk pemantauan stabilitas candi Borobudur dan bukit.

\section{Tujuan}

Tujuan studi ini adalah agar hasil pengukuran yang dilakukan lebih valid dengan orientasi tingkat ketelitian/akurasi yang dihasilkan lebih tinggi dan dapat dimanfaatkan secara optimal sehingga dapat diketahui berbagai kemungkinan yang berkaitan dengan deformasi yang terjadi pada candi Borobudur.

\section{Manfaat}

Hasil studi akan bermanfaat untuk pengembangan metode pengukuran untuk monitoring stabilitas candi Borobudur dan bukit khususnya, maupun bangunan cagar budaya lainnya yang rentan terhadap deformasi baik horisontal maupun vertikal, dan dapat dilakukan oleh tenaga teknis sesuai dengan peralatan yang tersedia.

\section{E. Ruang Lingkup}

Studi ini membatasi ruang lingkup kajian yaitu pengukuran jaring kontrol deformasi yang dilakukan hanya pada kerangka poligon utama (poligon III) yang terletak di halaman atas candi.

\section{F. Kerangka Pikir}

Alur atau kerangka berpikir dari studi evaluasi metode pengukuran stabilitas candi Borobudur dan bukit dapat dijelaskan dari diagram alir di bawah ini :

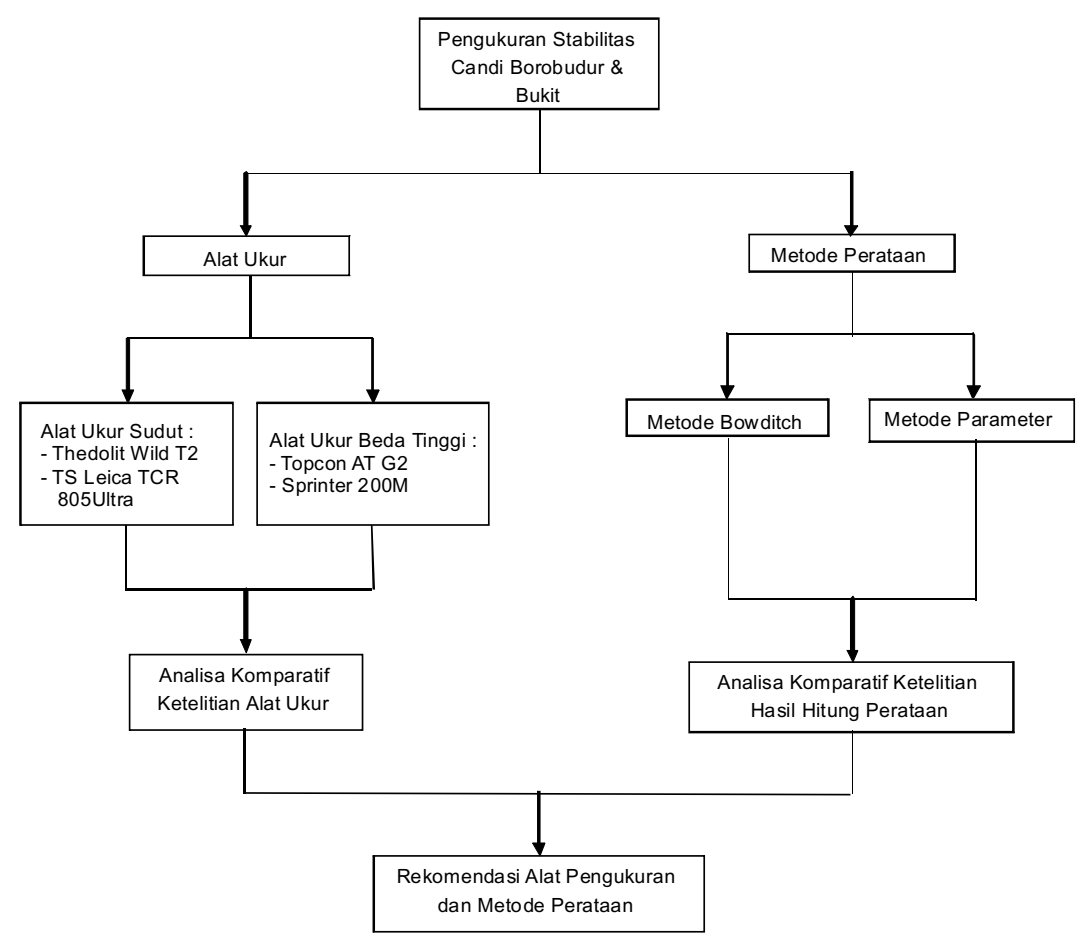

Gambar 5 : Skema alur penelitian

\section{Metodologi}

A. Alat dan Bahan

I. Peralatan yang digunakan untuk mengukur Sudut:

1. Theodolit Total Station Leica TCR 805 Ultra

2. Theodolit WildT2

3. Statif

4. Tribach dan reflektor

5. Alat bantu lainnya, seperti payung dan alat tulis

2. Peralatan yang digunakan untuk mengukur jarak:

1. EDM pada Total Station Leica TCR 805 Ultra

2. Statif

3. Tribach dan reflektor

4. Alat bantu lainnya, seperti payung dan alat tulis 
3. Peralatan yang digunakan untuk mengukur beda tinggi

1. Sipat datar tipe otomatik Topcon AT G2 yang dilengkapi dengan pembacaan micrometer.

2. Sipat datar digital Sprinter 200M dengan rambu barcode

3. Rambu ukur invar yang dilengkapi dengan nivo rambu

4. Konstruksi statif kaku

5. Alat bantu lainnya, seperti payung dan alat tulis

4. Software Matlab versi 6 untuk membuat program hitungan kuadrat terkecil metode parameter.

B. Metode Pelaksanaan

Studi ini dilaksanakan melalui beberapa tahap pelaksanaan yang dapat diurutkan sebagai berikut:

1. Persiapan dengan mengumpulkan sejumlah literatur referensi dari penelitian yang telah dilakukan.

2. Penyusunan proposal.

3. Pengumpulan data lapangan berupa pengukuran sudut, jarak, azimuth, dan beda tinggi.

- Pengukuran jarak dilakukan 16 kali (8 kali pengukuran pergi dan 8 kali pengukuran pulang).

- Pengukuran sudut dilakukan 2 seri rangkap.

- Pengukuran beda tinggi dilakukan 4 kali (2 kali pengukuran pergi dan 2 kali pengukuran pulang).

5. Pengolahan data dan analisa hasil pengukuran.

a. Analisa komparatif ketelitian alat ukur.

b. Analisa komparatif ketelitian metode perataan.

6. Penulisan laporan hasil studi.

\section{Hasil dan Pembahasan}

A. Hasil Pengukuran Jarak

\begin{tabular}{|c|c|c|}
\hline & Jarak Rata-rata & Ketelitian \\
\hline & (meter) & (milimeter) \\
\hline d1 & 63.8741 & 1.153 \\
\hline d2 & 59.2017 & 1.503 \\
\hline d3 & 67.5391 & 5.471 \\
\hline d4 & 69.2146 & 1.162 \\
\hline d5 & 69.8130 & 1.360 \\
\hline d6 & 53.6977 & 0.970 \\
\hline d7 & 61.1617 & 0.222 \\
\hline d8 & 60.4152 & 0.879 \\
\hline & & 1.590 \\
\hline
\end{tabular}

Tabel 1 : Hasil pengukuran jarak
B. Hasil Pengukuran Sudut

\begin{tabular}{|c|c|c|c|c|}
\hline & \multicolumn{2}{|c|}{ T2 } & \multicolumn{2}{c|}{ TS } \\
\hline & $\begin{array}{c}\text { Sudut } \\
\text { Ketelitian } \\
\text { (detik) }\end{array}$ & $\begin{array}{c}\text { Sudut } \\
\text { Ketelitian } \\
\text { (detik) }\end{array}$ \\
\hline$\beta_{1}$ & $150^{\circ} 28^{\prime} 44^{\prime \prime}$ & $0^{\circ} 0^{\prime} 2^{\prime \prime}$ & $150^{\circ} 28^{\prime} 27^{\prime \prime}$ & $0^{\circ} 0^{\prime} 22^{\prime \prime}$ \\
\hline$\beta_{2}$ & $119^{\circ} 42^{\prime} 37^{\prime \prime}$ & $0^{\circ} 0^{\prime} 2^{\prime \prime}$ & $119^{\circ} 42^{\prime} 19^{\prime \prime}$ & $0^{\circ} 0^{\prime} 8^{\prime \prime}$ \\
\hline$\beta_{3}$ & $156^{\circ} 26^{\prime} 48^{\prime \prime}$ & $0^{\circ} 0^{\prime} 3^{\prime \prime}$ & $156^{\circ} 26^{\prime} 15^{\prime \prime}$ & $0^{\circ} 0^{\prime} 2^{\prime \prime}$ \\
\hline$\beta_{4}$ & $104^{\circ} 26^{\prime} 40^{\prime \prime}$ & $0^{\circ} 0^{\prime} 2^{\prime \prime}$ & $104^{\circ} 26^{\prime} 42^{\prime \prime}$ & $0^{\circ} 0^{\prime} 3^{\prime \prime}$ \\
\hline$\beta_{5}$ & $153^{\circ} 33^{\prime} 38^{\prime \prime}$ & $0^{\circ} 0^{\prime} 2^{\prime \prime}$ & $153^{\circ} 33^{\prime} 30^{\prime \prime}$ & $0^{\circ} 0^{\prime} 4^{\prime \prime}$ \\
\hline$\beta_{6}$ & $127^{\circ} 37^{\prime} 57^{\prime \prime}$ & $0^{\circ} 0^{\prime} 1^{\prime \prime}$ & $127^{\circ} 38^{\prime} 24^{\prime \prime}$ & $0^{\circ} 0^{\prime} 4^{\prime \prime}$ \\
\hline$\beta_{7}$ & $139^{\circ} 15^{\prime} 36^{\prime \prime}$ & $0^{\circ} 0^{\prime} 3^{\prime \prime}$ & $139^{\circ} 15^{\prime} 21^{\prime \prime}$ & $0^{\circ} 0^{\prime} 3^{\prime \prime}$ \\
\cline { 2 - 5 }$\beta_{8}$ & $128^{\circ} 28^{\prime} 8^{\prime \prime}$ & $0^{\circ} 0^{\prime} 3^{\prime \prime}$ & $128^{\circ} 27^{\prime} 56^{\prime \prime}$ & $0^{\circ} 0^{\prime} 3^{\prime \prime}$ \\
\hline$\alpha_{12}$ & $284^{\circ} 0^{\prime} 41^{\prime \prime}$ & $0^{\circ} 0^{\prime} 2^{\prime \prime}$ & $284^{\circ} 0^{\prime} 53^{\prime \prime}$ & $0^{\circ} 0^{\prime} 3^{\prime \prime}$ \\
\hline & & $0^{\circ} 0^{\prime} 2^{\prime \prime}$ & & $0^{\circ} 0^{\prime} 4^{\prime \prime}$ \\
\hline
\end{tabular}

Tabel 2 : Perbandingan ketelitian alat ukur sudut

C. Hasil Pengukuran Beda Tinggi

\begin{tabular}{|c|c|c|cc|}
\hline \multirow{2}{*}{} & \multicolumn{2}{|c|}{ TOPCON AT G2 } & \multicolumn{2}{c|}{ LEICA SPRINTER 200M } \\
\cline { 2 - 5 } & Beda Tinqqi Rata2 & Ketelitian & Beda Tinqqi Rata2 & Ketelitian \\
\cline { 2 - 5 } dh1 & (meter) & (milimeter) & (meter) & (milimeter) \\
\hline dh2 & 0.409765 & 0.02677 & 0.407875 & 0.49917 \\
\hline dh3 & 0.070150 & 0.03464 & 0.070875 & 0.89954 \\
\hline dh4 & -0.000332 & 0.33869 & -0.001400 & 0.58878 \\
\hline dh5 & -0.220145 & 0.02273 & -0.221500 & 0.57155 \\
\hline dh6 & 0.300054 & 0.01931 & 0.300325 & 0.26300 \\
\hline dh7 & -0.120104 & 0.29573 & -0.119075 & 0.22174 \\
\hline dh8 & -0.249829 & 0.03326 & -0.247800 & 0.51640 \\
\hline dh9 & 0.154886 & 0.03038 & 0.153450 & 0.17321 \\
\hline & 0.064954 & 0.04922 & 0.064800 & 0.46904 \\
\hline
\end{tabular}

Tabel 3 : Perbandingan ketelitian alat ukur sipat datar

D. Hitung Perataan Metode Bowditch

\begin{tabular}{|c|c|c|c|c|}
\hline \multirow[b]{2}{*}{ Titik } & \multicolumn{2}{|c|}{$\mathrm{T} 2$} & \multicolumn{2}{|c|}{ TS } \\
\hline & $\mathrm{X}$ & $Y$ & $\mathrm{X}$ & $Y$ \\
\hline 1PIII & 200.0000 & 201.1170 & 200.0000 & 201.1170 \\
\hline 2PIII & 138.0279 & 216.5825 & 138.0264 & 216.5882 \\
\hline 3PIII & 122.0109 & 273.5765 & 122.0129 & 273.5857 \\
\hline 4PIII & 131.2430 & 340.4826 & 131.2569 & 340.4920 \\
\hline 5PIII & 200.0022 & 348.4256 & 200.0148 & 348.4262 \\
\hline 6PIII & 265.6689 & 324.7200 & 265.6752 & 324.7126 \\
\hline 7PIII & 282.0691 & 273.5881 & 282.0744 & 273.5828 \\
\hline 8PIII & 258.2136 & 217.2718 & 258.2162 & 217.2687 \\
\hline
\end{tabular}

Tabel 4 : Koordinat horisontal Poligon III (Metode Bowditch) 
Ketelitian yang dapat diperoleh dari perataan metode Bowditch hanya ketelitian linier sedangkan untuk ketelitian dari tiap titik koordinat tidak dapat diketahui. Ketelitian linier diperoleh dari persamaan kesalahan linier yaitu $\sqrt{ } d_{x}^{2}+d_{y}^{2}$.

Ketelitian linier dari

$\mathrm{T} 2=\sqrt{ }(-0.01321)^{2}+(-0.00502)^{2}$

$=1.4 \mathrm{~cm}$

Ketelitian linier dari

TS $=\sqrt{ }(-0.00577)^{2}+(-0.02135)^{2}$

$=2.2 \mathrm{~cm}$

E. Hitung Perataan Kuadrat Terkecil Metode Parameter

Dari tabel 5 dapat dilihat bahwa ketelitian yang diperoleh dari tiap koordinat, untuk T2 antara $1.9 \mathrm{~mm}$ sampai $2.4 \mathrm{~mm}$, dan untuk TS antara $2 \mathrm{~mm}$ sampai 2.5 $\mathrm{mm}$.

Dalam proses hitungan, iterasi dihentikan pada tingkat konvergensi tertentu dalam hal ini nilai koreksi parameternya lebih kecil dari $0.001 \mathrm{~m}$. Hasil hitungan parameter pada iterasi kelima telah diperoleh nilai seperti yang diinginkan dimana nilai koreksi parameter terbesar untuk T2 adalah 0.00003691 sedangkan untuk TS nilai koreksi parameter terbesar adalah 0.00024237. Nilai ini cukup kecil dan tidak terpengaruh terhadap nilai parameter itu sendiri.

Uji Statistik Hasil Hitung Perataan Metode Parameter

Pengujian dilakukan dengan uji global menggunakan tabel fungsi Fisher dengan taraf uji 95\% dan derajat kebebasan $(\mathrm{f})=\mathrm{n}-\mathrm{u}=17-14=3$. Dengan nol dapat diterima apabila persyaratan berikut dapat dipenuhi :

$$
\left.\sigma_{0}^{\prime 2} / \sigma_{0}^{2}<\mathrm{F}_{(95 \%, 3,30)}\right)
$$

Hasil uji terhadap varian aposteriori menunjukkan bahwa persyaratan dapat dipenuhi dengan hasil hitungan $1.36<2.61$ untuk T2 dan 1.53 $<2.61$ untuk TS. Penerimaan hipotesa nol merupakan indikasi bahwa pengamatan tidak dipengaruhi kesalahan tak acak.

F. Hitung Perataan Beda Tinggi

\begin{tabular}{|cc|c|c|c|}
\hline \multicolumn{2}{|c|}{ Titik } & \multicolumn{2}{c|}{ Sprinter } & \multicolumn{2}{c|}{ Topcon } \\
\hline & $Z(\mathrm{~m})$ & $\sigma Z(\mathrm{~mm})$ & $Z(\mathrm{~m})$ & $\sigma Z(\mathrm{~mm})$ \\
\hline & & & & \\
\hline 1 & 265.6912 & 0.165 & 265.6932 & 0.051 \\
\hline & & & & \\
\hline 2 & 265.4435 & 0.141 & 265.4454 & 0.045 \\
\hline & & & & \\
\hline 3 & 265.5970 & 0.138 & 265.5988 & 0.040 \\
\hline & & & & \\
\hline 4 & 265.6618 & 0.103 & 265.6636 & 0.019 \\
\hline & & & & \\
\hline 5 & 265.7328 & 0.178 & 265.7345 & 0.031 \\
\hline & & & & \\
\hline 6 & 265.7315 & 0.181 & 265.7333 & 0.163 \\
\hline & & & & \\
\hline 7 & 265.5100 & 0.172 & 265.5118 & 0.163 \\
\hline & & & & \\
\hline 8 & 265.8103 & 0.168 & 265.8121 & 0.162 \\
\hline
\end{tabular}

Tabel 6 : Koordinat vertikal Poligon III

\begin{tabular}{|c|c|c|c|c|c|c|c|c|}
\hline Titik & \multicolumn{5}{|c|}{ T2 } & \multicolumn{3}{c|}{ TS } \\
\hline & $\mathrm{X}(\mathrm{m})$ & $\sigma \times(\mathrm{m})$ & $\mathrm{Y}(\mathrm{m})$ & $\sigma \mathrm{V}(\mathrm{m})$ & $\mathrm{X}$ & $\sigma \times(\mathrm{m})$ & $\mathrm{Y}$ & $\sigma \mathrm{V}(\mathrm{m})$ \\
\hline & & & & & & & & \\
\hline 1 & 200.0000 & 0.0000 & 201.1170 & 0.0000 & 200.0000 & 0.0000 & 201.1170 & 0.0000 \\
\hline & & & & & & & & \\
\hline 2 & 138.0280 & 0.0020 & 216.5824 & 0.0005 & 138.0271 & 0.0021 & 216.5875 & 0.0005 \\
\hline & & & & & & & & \\
\hline 3 & 122.0109 & 0.0020 & 273.5764 & 0.0019 & 122.0134 & 0.0021 & 273.5841 & 0.0021 \\
\hline & & & & & & & & \\
\hline 4 & 131.2429 & 0.0020 & 340.4825 & 0.0023 & 131.2569 & 0.0021 & 340.4944 & 0.0024 \\
\hline & & & & & & & & \\
\hline 5 & 200.0021 & 0.0024 & 348.4255 & 0.0023 & 200.0141 & 0.0025 & 348.4292 & 0.0024 \\
\hline & & & & & & & & \\
\hline 6 & 265.6688 & 0.0021 & 324.7198 & 0.0023 & 265.6758 & 0.0022 & 324.7158 & 0.0024 \\
\hline & & & & & & & & \\
\hline 7 & 282.0688 & 0.0019 & 273.5878 & 0.0018 & 282.0754 & 0.0020 & 273.5845 & 0.0019 \\
\hline & & & & & & & & \\
\hline 8 & 258.2133 & 0.0019 & 217.2717 & 0.0005 & 258.2169 & 0.0021 & 217.2692 & 0.0006 \\
\hline
\end{tabular}

Tabel 5 : Koordinat horisontal Poligon III (Metode Parameter)

demikian nilai statistik $\left.\mathrm{F}_{(95 \%, 3, \infty}\right)$ dari tabel fungsi Fisher dapat ditentukan:

$$
\left.\mathrm{F}_{(95 \%, 3,0)}\right)=2.61
$$

Penetapan varian apriori $=1$ maka diperoleh nilai $\sigma_{0}^{\prime 2} / \sigma_{0}^{2}$ $=1.36$ untuk T2 dan $\sigma_{\circ}^{\prime 2} / \sigma_{o}^{2}=1.53$ untuk TS. Hipotesa

\section{Kesimpulan dan Saran}

A. Kesimpulan

Setelah dilakukan studi evaluasi tentang alat dan metode hitung perataan dalam rangka pelaksanaan pengukuran stabilitas candi Borobudur dan bukit, maka dapat diambil kesimpulan sebagai berikut:

1. Pada pengukuran jarak sisi poligon III menggunakan alat EDM TS Leica TCR805 Ultra diperoleh ketelitian terbesar 0.2 $\mathrm{mm}$ (d7) dan ketelitian

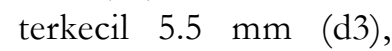
sedangkan ketelitian rata-rata dari 8 ukuran jarak adalah $1.6 \mathrm{~mm}$.

2. Pada pengukuran sudut poligon III untuk alat 
T2 diperoleh ketelitian dari 1 detik sampai 3 detik dan ketelitian rata-rata dari 9 ukuran sudut sebesar 2 detik, sedangkan untuk alat TS diperoleh ketelitian dari 2 detik sampai 8 detik dan ketelitian rata-rata dari 9 ukuran sudut sebesar 4 detik. Sehingga bisa ditarik kesimpulan bahwa Theodolit Wild T2 lebih teliti dari TS Leica TCR805 Ultra.

3. Pada pengukuran beda tinggi poligon III untuk alat Topcon AT G2 dengan rambu invar diperoleh ketelitian terbesar $0.0193 \mathrm{~mm}$ dan ketelitian terkecil $0.3387 \mathrm{~mm}$ dan ketelitian ratarata dari 9 ukuran beda tinggi adalah sebesar 0.09 $\mathrm{mm}$, sedangkan untuk alat Leica Sprinter 200M dengan rambu barcode diperoleh ketelitian terbesar $0.1732 \mathrm{~mm}$ dan ketelitian terkecil 0.8995 $\mathrm{mm}$ dan ketelitian rata-rata dari 9 ukuran beda tinggi adalah sebesar $0.5 \mathrm{~mm}$. Sehingga bisa disimpulkan bahwa Topcon AT G2 dengan rambu invar mempunyai tingkat ketelitian yang lebih tinggi dari Leica Sprinter 200M.

4. Ketelitian yang diperoleh dari hitung perataan metode bowditch adalah ketelitian linier sebesar $1.413 \mathrm{~cm}$ untuk alat T2 dan $2.212 \mathrm{~cm}$ untuk alat TS namun tidak bisa diperoleh ketelitian dari tiap titik koordinat poligon III.

5. Ketelitian koordinat horisontal poligon III yang diperoleh dari hitung perataan kuadrat terkecil metode parameter untuk alat $\mathrm{T} 2$ adalah terbesar $1.9 \mathrm{~mm}$ pada titik 7 dan terkecil $2.4 \mathrm{~mm}$ pada titik 5 , sedangkan untuk alat TS adalah terbesar $2 \mathrm{~mm}$ pada titik 7 dan terkecil $2.5 \mathrm{~mm}$ pada titik 5 .

6. Ketelitian koordinat vertikal poligon III yang diperoleh dari hitung perataan kuadrat terkecil metode parameter untuk alat Topcon adalah terbesar $0.019 \mathrm{~mm}$ pada titik 4 dan terkecil 0.163 $\mathrm{mm}$ pada titik 6 dan 7 , sedangkan untuk alat Sprinter adalah terbesar $0.103 \mathrm{~mm}$ pada titik 4 dan terkecil $0.181 \mathrm{~mm}$ pada titik 6 .

7. Hasil uji statistik dari varian aposteriori menunjukkan bahwa data pengamatan hasil pengukuran tidak mengandung kesalahan tak acak.

B. Saran

Berdasarkan temuan yang diperoleh dalam studi ini, berikut ini beberapa saran yang dapat disampaikan:

1. Alat ukur jarak yang disarankan untuk pengukuran jarak sisi poligon III yaitu dengan menggunakan EDM TS Leica TCR 805 Ultra.

2. Dari alat ukur sudut yang ada di kantor BKPB maka untuk pengukuran sudut dari jaring kontrol horisontal di candi Borobudur sebaiknya menggunakan Theodolit Wild T2.

3. Dari alat ukur sipat datar yang ada di kantor BKPB maka untuk pengukuran jaring kontrol vertikal di candi Borobudur sebaiknya menggunakan Topcon AT G2 dengan rambu invar.

4. Untuk menghitung koordinat jaring kontrol deformasi candi Borobudur baik horisontal maupun vertikal sebaiknya menggunakan hitung kuadrat terkecil metode parameter sedangkan metode Bowditch tetap digunakan tapi hanya untuk memperoleh koordinat pendekatan.

5. Untuk mendapatkan hasil ketelitian yang lebih tinggi lagi maka untuk pengukuran jaring deformasi candi Borobudur secara terestris nantinya dapat dipadukan dengan pengukuran menggunakan GPS tipe geodetik.

\section{DAFTAR PUSTAKA}

Siswojo, B., dkk., 2000, Studi Pengembangan Teknik Pemantauan Stabilitas Bangunan Cagar Budaya, Laporan Kajian, Balai Konservasi Peninggalan Borobudur, Magelang

Thohir, M., 2000, Studi Deformasi Status Geometrik Dua Dimensi pada Candi Borobudur, Skripsi, Jurusan Teknik Geodesi, Fakultas Teknik, Universitas Gadjah Mada, Yogyakarta

Ma'ruf, B., dkk., 2001, Pengadaan Jaring Kontrol Deformasi Dengan Menggunakan GPS Di Kawasan Candi Borobudur, Jurnal Surveying dan Geodesi, Vol. XI, No. 2, Yogyakarta

Siswojo, B., dkk., 2002, Pemantanan Deformasi Horizontal Candi Borobudur Dengan Metode Jaring Segitiga, Laporan Kajian, Balai Konservasi Peninggalan Borobudur, Magelang

Ma'ruf, B., 2003, Analisis Regangan Horisontal Situs Borobudur, Laporan Penelitian, Jurusan Teknik Geodesi, Fakultas Teknik, Universitas Gadjah Mada, Yogyakarta

Ma'ruf, B., 2004, Analisis Deformasi Vertikal Candi Borobudur, Laporan Penelitian, Jurusan Teknik Geodesi, Fakultas Teknik, Universitas Gadjah Mada, Yogyakarta

Siswojo, B., dkk., 2004, Studi Pengukuran Sipat Datar Teliti Titik-Titik. Kontrol Acuan GPS Candi Borobudur, Laporan Kajian, Balai Konservasi Peninggalan Borobudur, Magelang 